Published in final edited form as:

J Am Chem Soc. 2016 September 7; 138(35): 11176-11184. doi:10.1021/jacs.6b04915.

\title{
OxaD, a versatile indolic nitrone synthase from the marinederived fungus Penicillium oxalicum F30
}

\author{
Sean A. Newmister ${ }^{\dagger, \uparrow, ~ C l a i r e ~ M . ~ G o b e r ~}{ }^{\ddagger}$,, Stelamar Romminger ${ }^{\dagger}$, Fengan $\mathrm{Yu}^{\dagger}$, Ashootosh \\ Tripathi $^{\dagger}$, Lizbeth Lorena L. Parra ${ }^{\S}$, Robert M. Williams ${ }^{\otimes, \nabla}$, Roberto G.S. Berlinck ${ }^{\S},{ }^{*}$, \\ Madeleine M. Joullie ${ }^{\ddagger},{ }^{*}$, and David H. Sherman ${ }^{\dagger, \|, \perp, \#,{ }^{*}}$ \\ †Life Sciences Institute, University of Michigan, Ann Arbor, Michigan 48109, United States \\ IIDepartment of Medicinal Chemistry, University of Michigan, Ann Arbor, Michigan 48109, United \\ States \\ ${ }^{\perp}$ Department of Chemistry, University of Michigan, Ann Arbor, Michigan 48109, United States \\ \#Department of Microbiology \& Immunology, University of Michigan, Ann Arbor, Michigan 48109, \\ United States \\ ‡Department of Chemistry, University of Pennsylvania, 231 South 34th Street, Philadelphia, \\ Pennsylvania 19104, United States \\ §Instituto de Quimica de Sao Carlos, Universidade de Sao Paulo, CP 780, CEP 13560-970 Sao \\ Carlos, SP, Brazil \\ ${ }^{\otimes}$ Department of Chemistry, Colorado State University, Fort Collins, Colorado 80523, United \\ States \\ $\nabla$ University of Colorado Cancer Center, Aurora, Colorado 80045, United States
}

\section{Abstract}

Indole alkaloids are a diverse class of natural products known for their wide range of biological activities and complex chemical structures. Rarely observed in this class are indolic nitrones, such as avrainvillamide and waikialoid, which possess potent bioactivities. Herein the oxa gene cluster from the marine-derived fungus Penicillium oxalicum F30 is described along with the characterization of $\mathrm{OxaD}$, a flavin-dependent oxidase that generates roquefortine $\mathrm{L}$, a nitronebearing intermediate in the biosynthesis of oxaline. Nitrone functionality in roquefortine $\mathrm{L}$ was confirmed by spectroscopic methods and 1,3-dipolar cycloaddition with methyl acrylate. OxaD is a versatile biocatalyst that converts an array of semisynthetic roquefortine $\mathrm{C}$ derivatives bearing indoline systems to their respective nitrones. This work describes the first implementation of a nitrone synthase as a biocatalyst and establishes a novel platform for late-stage diversification of a range of complex natural products.

\footnotetext{
“Corresponding Authors: rgsberlinck@iqsc.usp.br, mjoullie@sas.upenn.edu, davidhs@umich.edu.

IThese authors contributed equally to this work.

The authors declare no competing financial interest.

Supporting Information. Full experimental details and NMR spectra are available free of charge via the Internet at http://pubs.acs.org.
} 


\section{Graphical Abstract}

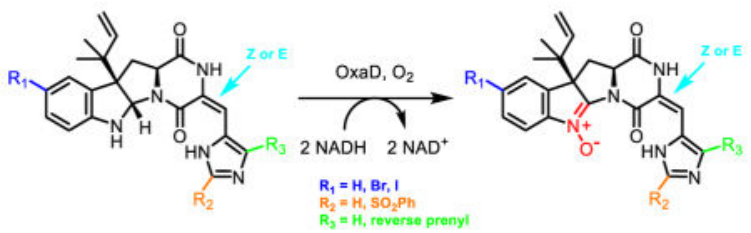

\section{INTRODUCTION}

Prenylated indole fungal alkaloids constitute a structurally complex class of natural products, for which potent antibacterial, anticancer, antiparasitic, and insecticidal activities have been reported. ${ }^{1,2}$ These alkaloids are typically derived from a tryptophan-proline diketopiperazine skeleton, with a prenyl group frequently attached in the reverse orientation to the indole moiety. The biosynthesis of fungal prenylated indole alkaloids involves a multistep cascade of reactions beginning with a non-ribosomal peptide synthetase (NRPS) catalyzed assembly of the diketopiperazine core. Subsequent sets of enzymes catalyze various oxidative/reductive reactions, C-C coupling, rearrangements, and in some cases, Diels-Alder reactions. ${ }^{1,2}$

Roquefortines, glandicolines, meleagrin and oxaline comprise a select group of biosynthetically related prenylated indole alkaloids (Fig. 1). The archetypic roquefortine $\mathrm{C}$ (1) was first isolated from Penicillium roqueforti and has been detected in over 30 different Penicillium species. ${ }^{3-5}$ Oxaline (2) and meleagrin (3) have been less frequently isolated from fungal cultures. ${ }^{6,7}$ Roquefortine $\mathrm{C}(\mathbf{1})$ is found in low levels in industrially produced blue cheese, ${ }^{8}$ grain, ${ }^{9-12}$ and animal feedstocks,${ }^{13}$ and while cytotoxic effects of varying degrees have been observed in mice ${ }^{14,15}$ and cockerels, ${ }^{16}$ roquefortine $\mathrm{C}$ has shown little to no cytotoxicity in a number of human cell lines. ${ }^{12,17,18}$ Roquefortine $\mathrm{C}$ is known to bind to iron, inactivating hepatic cytochrome $\mathrm{P} 450 \mathrm{~s}^{19}$ and inhibiting growth of gram-positive bacteria containing heme proteins. ${ }^{20,21}$ Roquefortine $\mathrm{C}$ may also be significant in indoor air contamination, as it has been isolated from numerous mold-contaminated indoor environments. Inflammatory responses have been reported for mouse lungs intratracheally instilled with roquefortine C. ${ }^{14,23-25}$ Despite their threat to human and animal health, as well as the economic loss due to food contamination by these compounds, ${ }^{26} \mathbf{1 - 3}$ have also attracted interest as potential therapeutics. Recent reports indicate that $\mathbf{3}$ is a promising lead for the treatment of breast cancer, ${ }^{27}$ while meleagrin B, a diterpene-substituted biosynthetic derivative of $\mathbf{3}$, was shown to induce HL-60 cell apoptosis. ${ }^{28}$ Additionally, $\mathbf{3}$ has demonstrated inhibition of bacterial type II fatty acid synthesis while $\mathbf{2}$ has been shown to inhibit tubulin polymerization in Jurkat cells. ${ }^{29,30}$

Oxaline (2) and meleagrin (3) feature a triazaspirocyclic skeleton derived from an unusual rearrangement of the diketopiperazine core of $\mathbf{1} .^{22}$ The first proposed mechanism for the biosynthesis of $\mathbf{2}$ from $\mathbf{1}$ included the formation of a 1,4-diazonane-2,5,6-trione intermediate $\mathbf{6}$ as the key step, prior to the transannular attack of the indole by the histidine-derived $\mathbf{a}$ nitrogen, leading to the formation of the tri-nitrogen-substituted core in $\mathbf{2}$ and $\mathbf{3} .^{22}$ 
Experiments performed with cultures of $P$. glandicola, $P$. atramentosum and $P$. farinosum provided additional evidence that glandicolines A (4) and B (5), meleagrin (3), and oxaline (2) are derived from roquefortine $\mathrm{C}(\mathbf{1}){ }^{31}$

Whole genome sequencing, analysis, and substrate modeling with $P$. chrysogenum Wis54-1255 enabled the determination of the gene cluster that encodes the biosynthesis of 1. ${ }^{32}$ Open reading frames within the roquefortine-meleagrin gene cluster in the $P$. chrysogenum genome have been subjected to a series of RNA silencing experiments, which enabled a putative biochemical assignment for each step of the biosynthetic pathway. ${ }^{33}$ Transformation of roquefortine C (1) into glandicoline A (4) is promoted by a MAK1-like monooxygenase RoqM (encoded by Pc21g15460), as evidenced by loss of production of $\mathbf{3}$, 4, and 5 upon gene silencing. Subsequent gene deletion analysis of the $P$. chrysogenum strain DS54555 roquefortine $\mathrm{C}$ gene cluster ${ }^{34}$ confirmed the results obtained by gene silencing, ${ }^{33}$ leading to a mechanism identical to the one previously proposed by Steyn and Vleggaar. ${ }^{22}$ More recently, a rigorous structural elucidation of the metabolites of this pathway prompted a revision of the biosynthetic mechanism for this particular rearrangement. ${ }^{35}$ The key revision to this newly proposed metabolic pathway is the generation of the nitrone-bearing intermediate roquefortine L (7) by RoqM from 1 (Fig. 2). Since roquefortine L (7) has a molecular weight identical to that of glandicoline A (4), it was proposed that $\mathbf{7}$ had been mistakenly characterized as $\mathbf{4}$ in the initial gene silencing and gene deletion studies. Cytochrome P450 monooxygenase RoqO (encoded by Pc21g15450) was proposed to catalyze the rearrangement of $\mathbf{7}$ to give the triazaspirocyclic core of glandicoline B (5) as deletion of this gene resulted in loss of production of $\mathbf{5}$ and $\mathbf{3}$.

Fungal production of roquefortine L (7) is particularly relevant, since very few indoline nitrones are known as natural products. ${ }^{36-40}$ With the exception of the recently isolated versicamide $\mathrm{E}(\mathbf{8})$, alstoyunine $\mathrm{D}(\mathbf{9})$, and perakine $N^{1}, N^{4}$-dioxide (10), the remaining fungal indolic nitrones share a common avrainvillamide (11) core (Fig. 2). Nitrone incorporation into these compounds can promote several biologically relevant events. For example, the nitrone functional group on avrainvillamide is required for dimerization to stephacidin B (13). ${ }^{41}$ The nitrone function of avrainvillamide also plays a vital role in its anti-proliferative activity, with the proposed mechanism of anti-proliferation involving nucleophilic attack of the nitrone functionality by cysteine residues in cellular proteins. ${ }^{40,42-44}$ Such properties generate great interest in the chemical synthesis of these molecules. ${ }^{45-47}$

Chemical conversion of indolines into their respective nitrone has been reported in only a few instances. It requires either mild oxidative conditions to give very moderate yields, ${ }^{46,48}$ or a multi-step procedure affording good yield. ${ }^{49}$ Discovery of a biocatalyst that could efficiently perform such a reaction in a single high-yield step would be of major interest for the synthesis of nitrone functionalized indolines. Previous accounts of enzymatic nitrone formation have focused on metabolism of xenobiotic secondary amines and hydroxylamines by hepatic microsomal enzymes, ${ }^{50-57}$ however, in the majority of these instances, nitrone formation was accompanied by a number of additional oxidative side reactions. Therefore the complex and biologically active indole alkaloids remain important targets for this type of functionalization. 
We herein report the isolation, characterization, and enzymatic activity of $\mathrm{OxaD}$, which can be produced in significant yields by heterologous expression. OxaD is a flavoprotein that has been harnessed for the biocatalytic conversion of roquefortine $\mathrm{C}$ and roquefortine $\mathrm{C}$ semisynthetic derivatives to afford the resulting indoline nitrones in very good yield and in a single step. To the best of our knowledge, this work represents the first biocatalytic synthesis of indoline nitrones.

\section{RESULTS}

\section{Oxaline Biosynthetic Gene Cluster}

In order to investigate the biogenesis of oxaline in mechanistic detail, we sequenced the genome of $P$. oxalicum $\mathrm{F} 30$ and performed gene cluster analysis using antiSMASH followed by a deep annotation of the oxaline biosynthetic pathway (Gen- Bank: KX601657)(Scheme $1 \mathrm{~A}$, Table S1). The composition of the oxaline (oxa) gene cluster is highly similar to that of the roquefortine/meleagrin (roq) cluster from $P$. chrysogenum ${ }^{33}$ (Table S2), with an average $78.4 \%$ similarity between homologous ORFs in the respective systems. One exception is a second methyltransferase $(\mathrm{OxaC})$, which is absent in P. chrysogenum and suggests that this enzyme is responsible for the enol $O$-methylation that distinguishes 2 from 3 . By homology, we reason that the initial biosynthetic steps toward $\mathbf{2}$ match those previously reported for $\mathbf{3}$ (Scheme 1B) ${ }^{34,58,59}$. Briefly, the first biosynthetic intermediate His-Trp diketopiperazine (HTD, 16) is generated by an NRPS-mediated condensation of the corresponding L-amino acids. HTD undergoes reverse prenylation at $\mathrm{C}-3$ catalyzed by $\mathrm{OxaF}$ and dehydrogenation catalyzed by $\mathrm{OxaB}$ to give 1 . The flavin oxidase, $\mathrm{OxaD}$, and the $\mathrm{P} 450$ monooxygenase, OxaH, are homologous to P. chrysogenum RoqM and RoqO, respectively. RoqM and RoqO have been proposed to generate the core intermediate 5 from $\mathbf{1}$ by proceeding through intermediate $\mathbf{7}$, as identified by Ries et al. ${ }^{35}$ The conversion of $\mathbf{7}$ to $\mathbf{5}$ is proposed to arise from a P450-dependent hydroxylation catalyzed by $\mathrm{OxaH}$, although this transformation has not been observed in vitro. Two $O$-methylations by $\mathrm{OxaG}$ and $\mathrm{OxaC}$ generate the final product 2 (manuscript in preparation).

\section{OxaD is a flavin-dependent nitrone synthase}

OxaD was cloned from a $P$. oxalicum F30 cDNA library and heterologously expressed in Escherichia coli. The purified enzyme has an intense yellow color. HPLC-MS analysis of the supernatant of boiled OxaD shows near quantitative incorporation of flavin adenine dinucleotide (FAD) (Fig. S1). In order to obtain sufficient quantities of the starting substrate 1, a fermentation-based isolation using $P$. crustosum was developed. ${ }^{60}$ Gram quantities of pure 1 were obtained for enzymatic testing and chemical derivatization. Both NADH and NADPH were shown to be effective in the oxidation of $\mathbf{1}$ by OxaD. Incubation of OxaD with 1 and reduced nicotinamide cofactor resulted in the formation of several products (Fig. S2). After 4 hours incubation of 1 with OxaD, HPLC-MS analysis (50:50 MeOH: $\mathrm{H}_{2} \mathrm{O}$ ) showed peaks with molecular weights corresponding to the nitrone $\mathbf{7}$, the hydrated product $\mathbf{1 4}$, and a presumed $\mathrm{MeOH}$ adduct. Low levels of the hydroxylamine 15 (Fig. 3) were also detected. Preparative scale enzymatic reactions were conducted using $1(20 \mathrm{mg})$ in order to characterize the major reaction product. Since reverse-phase C18 chromatography led exclusively to the hydrolysis product $\mathbf{1 4}$, subsequent reactions were designed to minimize 
the exposure of $\mathbf{7}$ to aqueous conditions, acidic or basic $\mathrm{pH}$, and light. Biocatalytic reactions were performed for $1 \mathrm{~h}$ prior to extraction with EtOAc and normal phase chromatography purification on deactivated silica gel in the absence of small alcohols. These conditions led to $\mathbf{7}$ in a single step in good yield. The presence of the nitrone functionality in $\mathbf{7}$ was confirmed by analysis of ${ }^{1} \mathrm{H}$ NMR, ${ }^{13} \mathrm{C}$ NMR, and IR spectra. Additionally, P. crustosum was cultured on ${ }^{15} \mathrm{~N}$-enriched medium to give ${ }^{15} \mathrm{~N}$-labeled 1 ( $86 \%$ incorporation, Table S4). This material was subjected to the same reaction conditions as $\mathbf{1}$ to provide ${ }^{15} \mathrm{~N}$-labeled $\mathbf{7}$, which was characterized by ${ }^{15} \mathrm{~N}-\mathrm{NMR}$. Comparison with the spectrum for labeled $\mathbf{1}$ clearly demonstrated the presence of a nitrone at N-1 in roquefortine L (7) (Fig. S17). A final confirmation of the nitrone functionality in roquefortine $\mathrm{L}(7)$ resulted from its 1,3-dipolar cycloaddition with methyl acrylate (Scheme 2 , and vide infra).

\section{Investigating the mechanism of oxidation}

The observation of hydroxylamine 15 (Fig. 3) led us to investigate the mechanism of roquefortine $\mathrm{C}(\mathbf{1})$ oxidation by $\mathrm{OxaD}$. The full catalytic cycle encompasses a four-electron oxidation, in which two equivalents of reduced nicotinamide cofactor (NADH) are consumed en route to the nitrone product (Fig. S3). Therefore, a single turnover experiment was performed, in which only one equivalent of NADH was provided to equimolar concentrations of $\mathrm{OxaD}$ and roquefortine $\mathrm{C}$. Analysis of the reaction products showed an approximate 1:2 ratio of singly-oxidized hydroxylamine $\mathbf{1 5}$ species relatively to the doublyoxidized nitrone product (Fig. S3), conclusively demonstrating that the reaction proceeds through a hydroxylamine intermediate. The abundance of $\mathbf{1 5}$ with respect to $\mathbf{7}$ under single turnover conditions also suggested the possibility that oxidation by OxaD is catalyzed in an iterative rather than a processive manner. To further support this proposal, single-turnover reactions were performed using a 10 -fold stoichiometric excess of roquefortine $\mathrm{C}$ with respect to NADH and $\mathrm{OxaD}$ in an effort to preclude re-binding of the dissociated hydroxylamine species. Under these conditions, $\mathbf{1 5}$ was the dominant reaction product (Fig. S3), further supporting an iterative mechanism for OxaD. This iterative N-oxidation mechanism has been previously reported with human FMO3 using various substrates. ${ }^{61,62}$ The steady state kinetic constants of $\mathrm{OxaD}$ with roquefortine $\mathrm{C}$ were determined using an HPLC-based assay. These data show a $\mathrm{k}_{\text {cat }}$ of $0.017 \mathrm{~s}^{-1}$ with a $\mathrm{K}_{M}$ of $71 \mathrm{nM}$ resulting in a catalytic efficiency $\left(\mathrm{k}_{\text {cat }} / \mathrm{K}_{M}\right)$ of $2.3 \times 10^{5} \mathrm{M}^{-1} \times \mathrm{s}^{-1}$ (Fig. S4).

\section{Roquefortine C nitrone undergoes 1,3-dipolar cycloaddition}

As a means to further validate the enzymatic production of $\mathbf{7}$, and in order to explore indoline nitrones as a handle for further indole alkaloid diversification, 7 was screened with known dipolarophiles for 1,3-dipolar cycloaddition reactions. Methyl acrylate showed the best reactivity toward 7. Optimized reaction conditions generated cycloadduct $\mathbf{1 8}$ in a single step with $84 \%$ conversion, $24 \%$ yield (Scheme 2). The observed regiochemistry of this reaction is consistent with predictions based on frontier molecular orbital interactions. ${ }^{63}$

\section{Roquefortine $\mathrm{C}$ derivatives are converted to nitrones by $\mathrm{OxaD}$}

In order to explore the substrate scope of $\mathrm{OxaD}$, the roquefortine $\mathrm{C}$ derivatives $\mathbf{1 9}-\mathbf{2 3}$ were assayed under the same conditions as described above for the native substrate $\mathbf{1}$. Compounds 
$19-23$ were generated by semisynthesis from 1 (Fig. 4). Isoroquefortine C (19) was obtained by photochemical reaction of $\mathbf{1}$ using broad spectrum UV light. ${ }^{64}$ Electrophilic aromatic substitution of $\mathbf{1}$ using $N$-bromosuccinimide (NBS) and $N$-iodosuccinimide (NIS) yielded 11-bromoroquefortine $\mathrm{C}(\mathbf{2 0})^{65}$ and 11-iodoroquefortine $\mathrm{C}(\mathbf{2 1})$, respectively. Phenylsulfonylroquefortine C (22) was prepared using $N$-fluorobenzenesulfonimide (NFSI) as a phenylsulfonyl group transfer reagent. ${ }^{66}$ Roquefortine E (23) was purchased from Enzo (Ann Arbor, MI). Processing $\mathbf{1 9}-\mathbf{2 3}$ to their corresponding nitrone products (24-28) demonstrated that $\mathrm{OxaD}$ can accommodate variation at several positions in the roquefortine C skeleton.

Total turnover numbers (TTN) were measured in order to quantify the effect of these variations on the OxaD biocatalyst (Fig. 5). Modifications to the histidine moiety, including both alkene isomerization (24) and reverse prenylation (28), were well tolerated. Only the phenylsulfonyl derivative (22) showed a substantial decrease in TTN. In order to test whether the diminished turnover of $\mathbf{2 2}$ was observed due to the poor solubility of this substrate, TTNs were measured using both $10 \%$ and $20 \%$ DMSO cosolvent. While elevated cosolvent increased the solubilization of 22, only a modest increase in TTN was observed, likely indicating that the benefit was offset by attenuated enzymatic activity. Modifications to the indole ring via halogenation were also processed efficiently by $\mathrm{OxaD}$.

\section{OxaD catalyzes indole 2,3-oxidation of notoamide S}

Based on the broad reactivity that OxaD displayed with roquefortine $\mathrm{C}$ derivatives, additional indole alkaloids were subjected to the enzyme to examine whether this substrate flexibility extended beyond the roquefortine $\mathrm{C}$ scaffold. These include brevianamide $\mathrm{F}(\mathbf{2 9})$, 6-OH-deoxybrevianamide E (30), notoamide S (31), notoamide E (32), (+)-stephacidin A (33), notoamide T (34) and preparaherquamide (35) (Scheme 3A). Of particular interest was to assay $\mathbf{3 3}$, a presumed biosynthetic precursor to the nitrone bearing avrainvillamide (11);67 however no reaction was observed for substrates 29, 30, and 32-35. Enzyme-dependent generation of a new product with $m / z=+16$ Da was uniquely observed by LC-MS with 31 . The total conversion (20\%) was lower than that of the roquefortine $\mathrm{C}$ alkaloids. Biocatalytic reaction of $\mathbf{3 1}$ with OxaD yielded $\mathbf{3 6}$ (Scheme 3B), rather than the expected indole $\mathrm{N}$ hydroxylamine. The product $\mathbf{3 6}$ is presumed to arise via a pinacol-like rearrangement, following 2,3-epoxidation in an analogous fashion to the NotB catalyzed formation of notoamides C (37) and D (38) (Scheme 4). ${ }^{68}$

\section{DISCUSSION}

While the biosynthesis of the roquefortine $\mathrm{C}$ derived alkaloids 1-5 has been the subject of investigations employing genetic approaches, ${ }^{33-35}$ enzymatic characterization relating to assembly and processing steps is completely lacking for these indole alkaloid pathways. By sequencing the $P$. oxalicum $\mathrm{F} 30$ genome, we have identified the oxaline biosynthetic gene cluster, which is homologous to the meleagrin system. ${ }^{33}$ Large scale heterologous expression of the indoline nitrone synthase OxaD enabled its complete enzymatic characterization. OxaD catalyzes the key oxidation steps leading to the conversion of $\mathbf{1}$ to $\mathbf{5}$. It is a robust biocatalyst for nitrone installation on the wild type substrate roquefortine $\mathrm{C}$ as 
well as a range of structurally related alkaloids. Large quantities of $\mathbf{1}$, obtained by fermentation of $P$. crustosum, enabled semisynthetic preparation of roquefortine $\mathrm{C}$ analogues and preparative scale biocatalytic reactions with these substrates. $P$. crustosum produced 1 for a fraction of the cost of total synthesis ${ }^{69}$ and promotes green chemistry practices by avoiding the use of large quantities of organic solvents and unnecessary derivatizations.

Identification of nitrones has long been a challenge with regard to their differentiation from other products of $\mathrm{N}$-oxidation, such as imines, amine oxides, or oxaziridines. Since nitrones undergo 1,3 dipolar cycloadditions with dipolarophiles such as alkenes, alkynes, and nitriles, roquefortine $\mathrm{L}$ (7) was subjected to 1,3-dipolar cycloaddition with methyl acrylate to give 18, in agreement with the frontier molecular orbital interactions described by Sustmann and Trill. ${ }^{63}$ While this cycloaddition is highly indicative of the presence of a nitrone functionality in $\mathbf{7}$, oxaziridines are also known to thermally rearrange to nitrones before undergoing 1,3-dipolar cycloadditions..$^{70,71}$

Preparative scale (>20 mg) reactions of $\mathbf{1},{ }^{15} \mathrm{~N}$-enriched $\mathbf{1}, \mathbf{1 9}, \mathbf{2 0}$, and 22 with OxaD were conducted to provide sufficient material for spectroscopic analysis of nitrones $\mathbf{7 , 2 4}, \mathbf{2 5}$, and 27. Analysis of the ${ }^{1} \mathrm{H}$ NMR spectrum of $\mathbf{7}$ confirms the double oxidation event at the indoline nitrogen, demonstrated conclusively by the disappearance of the H-6 signal at $\delta$ $6.35 \mathrm{ppm}$. Moreover, chemical shifts of $\mathrm{H}-9, \mathrm{H}-10, \mathrm{H}-11$ and $\mathrm{H}-12$ were observed further downfield. Analysis of the ${ }^{13} \mathrm{C}$ NMR spectrum of 7 was further indicative of the nitrone formation, as the chemical shift of the C-6 peak shifted from $\delta 78 \mathrm{ppm}$ to $\delta 150 \mathrm{ppm}$. Additionally, previous infrared analysis of $N$-phenyl nitrones shows a very strong band between $1000-1100 \mathrm{~cm}^{-1}$ corresponding to the N-O stretch. ${ }^{72}$ This band disappears upon isomerization of $\mathrm{N}$-phenyl nitrones to the corresponding oxaziridines. Following the oxidation of roquefortine $\mathrm{C}$ by OxaD, an intense band was observed at $1014 \mathrm{~cm}^{-1}$ in the IR spectrum of 7, as additional support for the presence of a nitrone functionality instead of an oxaziridine. The presence of the nitrone group was also confirmed by analysis of ${ }^{1} \mathrm{H}_{-}{ }^{15} \mathrm{~N}$ HMBC spectrum of ${ }^{15} \mathrm{~N}$-enriched 7. Nitrogen atoms in $\mathrm{N}$-aryl nitrones display a characteristic peak between $\delta 270-300 \mathrm{ppm}$, while the corresponding amine nitrogens are observed between $\delta 0-100 \mathrm{ppm}$. In the ${ }^{1} \mathrm{H}_{-}{ }^{15} \mathrm{~N}$ HMBC spectrum of ${ }^{15} \mathrm{~N}$-enriched 7 the signal at $\delta 83 \mathrm{ppm}$ disappeared, and a new peak was observed at $\delta 281 \mathrm{ppm}$, which correlated to $\mathrm{H}-9$ and $\mathrm{H}-10$.

The enzymatic characterization of OxaD, along with the results of gene disruptions, ${ }^{34}$ indicates that formation of roquefortine L (7) is a key biosynthetic intermediate toward formation of the glandicoline core. OxaD conversion of $\mathbf{1}$ into $\mathbf{7}$ generates the electrophilic center required for the attack by the amide nitrogen in the proposed 1,4-diazonane-2,5,6trione intermediate (6) (Scheme 5). ${ }^{35}$ Hydroxylation at C-16 of $\mathbf{1}$ leading to $\mathbf{3 9}$ appears insufficient to induce rearrangement, since this metabolite has been previously isolated and identified; ${ }^{73,74}$ therefore, both hydroxylation at $\mathrm{C}-16$ and nitrone generation to give $\mathbf{4 1}$ are likely required for the core rearrangement to occur. Roquefortine L (7) involvement is supported by the fact that glandicoline A (5) has not been observed in P. chrysogenum, and that disruption of $\operatorname{roqM}(81 \%$ homology with $o x a D)$ abolished the production of glandicoline B (6). ${ }^{35}$ The first report of 5 in P. glandicola is sufficiently supported by spectroscopic data; ${ }^{75}$ however, subsequent reports of 5 were based on mass spectrometry 
analysis, chromatographic retention time $\left(\mathrm{R}_{\mathrm{f}}\right)$ and/or UV signature, but not by NMR analysis. ${ }^{31,33,34}$ As substantial structural characterization of metabolites is imperative in differentiating glandicoline A from 7, we have unequivocally assigned the nitrone group in $\mathbf{7}$ by NMR, IR, and chemical transformation.

At present, the mechanism of formation of $\mathbf{5}$ in P. glandicola is unclear. It could require a yet unknown route to the 1,2-imine in $\mathbf{4}$ proposed by Steyn and Vleggaar ${ }^{33}$ or arise by modification of 6 (Scheme 5). Investigation of the biosynthetic gene clusters in strains that produce $\mathbf{4}$ will be necessary to identify candidate enzymes that could give rise to $\mathbf{4}$, either through a different oxidation cascade involving $\mathbf{1}$ or enzymatic processing of $\mathbf{5}$. Understanding the role of the oxidative enzymes involved in the rearrangement of $\mathbf{1}$ to $\mathbf{5}$ will be critical for in vitro reconstitution and for future mutasynthetic efforts based on derivatives of $\mathbf{1}$. There is ample precedence for plasticity in these pathways, as mutasynthesis with roqA gene disruption mutant strains has been used to generate novel roquefortine D derivatives. ${ }^{76}$ Characterization of $\mathrm{OxaD}$ reported in this study also reveals the ability of the roquefortine $\mathrm{C}$ nitrone synthase to accept an array of modified substrates that enables the generation of novel indoline nitrones that would be synthetically appealing for the preparation of further elaborated alkaloid scaffolds.

Indole alkaloids $\mathbf{2 9}-\mathbf{3 5}$ were tested primarily as a means to define the substrate scope of OxaD and also to explore the possibility that a flexible OxaD enzyme could reveal a functional link between nitrone biogenesis in roquefortine L (7) and avrainvillamide (11). While no reaction was observed with OxaD and (+)-stephacidin A (33), OxaD was shown to catalyze oxidation of notoamide $\mathrm{S}$ (31) to the rearranged product 36. Surprisingly, in this case the enzyme catalyzed a 2,3-indole epoxidation rather than the expected $N$ hydroxylation. Compound $\mathbf{3 6}$ is likely derived from a pinacol-type rearrangement, as reported for the homologous NotB, which shows 53\% similarity and 37\% identity with OxaD (Scheme 3B). ${ }^{68}$ Compound $\mathbf{3 6}$ was observed as a single reaction product between $\mathbf{3 1}$ and OxaD, as opposed to the reaction between notoamide E (32) and NotB, which generated notoamides C (37) and D (38) (Scheme 4). OxaD appears to play a role in directing reaction selectivity, although low enzyme activity with notoamide $\mathrm{S}(\mathbf{3 1})$ could limit the detection of minor reaction products. This outcome shows that OxaD presents a remarkable functional plasticity in addition to its broad substrate scope. Indeed, bioinformatic analysis of OxaD reveals that biochemically characterized homologs promote a variety of oxidative reactions (Table S3), indicating that subtle structural differences likely enable these enzymes to differentially catalyze oxidative processes. Further structural investigation of $\mathrm{OxaD}$ or its structural and functional homologs would be required to determine the mechanistic basis of this branch in reaction specificity.

The discovery of $\mathrm{OxaD}$ as an indolic nitrone synthase enables a unique strategy in late stage chemical derivatization of nitrone functionalized indolines through 1,3-dipolar cycloadditions. There are limited reports of the occurrence of 1,3-dipolar cycloadditions using natural products or their biosynthetic intermediates as substrates. ${ }^{77}$ Roquefortine L (7) undergoes effective 1,3-dipolar cycloaddition with methyl acrylate to give $\mathbf{1 8}$ (Scheme 2), a derivatization outcome that may be extended to an array of other dipolarophiles with electron-withdrawing substituents. ${ }^{78}$ By coupling this derivatization strategy with the broad 
substrate scope of OxaD, we have established a platform in which novel indole alkaloid frameworks can be paired with an array of dipolarophiles in a cycloaddition cascade. Recent reports describing the therapeutic potential of $\mathbf{2}^{29}$ and $\mathbf{3}^{27,30}$ provide strong motivation to develop these tools. Future efforts in our laboratories will also seek to extend the substrate scope of OxaD beyond alkaloids in the roquefortine family.

\section{CONCLUSION}

The results herein illustrate that the combination of biological and chemical approaches for the generation of new and diverse natural products can lead to a number of applications in chemistry and chemical biology. Understanding the genetic and metabolic information of biosynthetic systems can provide access to complex chiral molecular scaffolds, which can be further synthetically elaborated into novel molecules. These natural product-based modified frameworks are of considerable interest in chemistry, biochemistry, and chemical biology as bioactive chemical entities or as unique biochemical tools. Heterologous production and enzymatic characterization of $\mathrm{OxaD}$ constitutes a proof of concept that unique biocatalysts can generate versatile and powerful chemical and biochemical tools for structural diversification.

\section{Supplementary Material}

Refer to Web version on PubMed Central for supplementary material.

\section{Acknowledgments}

Funding Sources

This work was supported by the NIH (CA070375), NSF CHE 1220121, the FAPESP (grants 2012/50026-3, 2013/50228-8 and 2014/05670-7), a post-doctoral fellowship awarded to SR (CAPES, BEX 4498/14-3), and predoctoral training grant fellowships awarded to CMG (NIH, 5T32GM071339-09, 5T32GM071339-10, 2T32GM071339-11).

The authors would like to thank Dr. George Furst, Dr. Jun Gu, and Dr. Wendy Feng for their support obtaining NMR spectra.

\section{References}

1. Li SM. Nat Prod Rep. 2010; 27:57. [PubMed: 20024094]

2. Finefield JM, Frisvad JC, Sherman DH, Williams RM. J Nat Prod. 2012; 75:812. [PubMed: 22502590]

3. Ohmomo S, Sato T, Utagawa T, Abe M. Agr Biol Chem Tokyo. 1975; 39:1333.

4. Ohmomo S, Utagawa T, Abe M. Agr Biol Chem Tokyo. 1977; 41:2097.

5. Polonsky J, Merrien MA, Scott PM. Ann Nutr Aliment. 1977; 31:963. [PubMed: 613945]

6. Qu P, Wu ZY, Zhu WM. Acta Crystallogr, Sect E: Struct Rep Online. 2012; 68:o1626.

7. Nagel DW, Pachler KGR, Steyn PS, Wessels PL, Gafner G, Kruger GJ. J Chem Soc, Chem Commun. 1974; :1021.doi: 10.1039/c39740001021

8. Hymery N, Vasseur V, Coton M, Mounier J, Jany JL, Barbier G, Coton E. Compr Rev Food Sci F. 2014; 13:437.

9. Driehuis F, Spanjer MC, Scholten JM, te Giffel MC. J Dairy Sci. 2008; 91:4261. [PubMed: 18946131]

10. Mansfield MA, Jones AD, Kuldau GA. Phytopathology. 2008; 98:330. [PubMed: 18944084] 
11. Spanjer MC, Rensen PM, Scholten JM. Food Addit Contam Part A Chem Anal Control Expo Risk Assess. 2008; 25:472. [PubMed: 18348046]

12. Rasmussen RR, Rasmussen PH, Larsen TO, Bladt TT, Binderup ML. Food Chem Toxicol. 2011; 49:31. [PubMed: 20837087]

13. Monbaliu S, Van Poucke C, Detavernier C, Dumoulin F, Van De Velde M, Schoeters E, Van Dyck S, Averkieva O, Van Peteghem C, De Saeger S. J Agric Food Chem. 2010; 58:66. [PubMed: 19994896]

14. Rand TG, Giles S, Flemming J, Miller JD, Puniani E. Toxicol Sci. 2005; 87:213. [PubMed: 15958659]

15. Arnold DL, Scott PM, McGuire PF, Harwig J, Nera EA. Food Cosmet Toxicol. 1978; 16:369. [PubMed: 711058]

16. Wagener RE, Davis ND, LDU. Appl Environ Microb. 1980; 39:882.

17. Larsen TO, Gareis M, Frisvad JC. J Agric Food Chem. 2002; 50:6148. [PubMed: 12358494]

18. Bunger J, Westphal G, Monnich A, Hinnendahl B, Hallier E, Muller M. Toxicology. 2004; 202:199. [PubMed: 15337583]

19. Aninat C, Andre F, Delaforge M. Food Addit Contam. 2005; 22:361. [PubMed: 16019806]

20. Kopp-Holtwiesche BB. J Environ Pathol Toxicol Oncol. 1990; 10:41. [PubMed: 2231314]

21. Kopp B, Rehm HJ. Eur J Appl Microbiol Biotechnol. 1979; 6:397.

22. Steyn PS, Vleggaar R. J Chem Soc, Chem Commun. 1983; 10:560.

23. Vishwanath V, Sulyok M, Labuda R, Bicker W, Krska R. Anal Bioanal Chem. 2009; 395:1355. [PubMed: 19669641]

24. Taubel M, Sulyok M, Vishwanath V, Bloom E, Turunen M, Jarvi K, Kauhanen E, Krska R, Hyvarinen A, Larsson L, Nevalainen A. Indoor Air. 2011; 21:368. [PubMed: 21585551]

25. Vishwanath V, Sulyok M, Weingart G, Kluger B, Taubel M, Mayer S, Schuhmacher R, Krska R. Talanta. 2011; 85:2027. [PubMed: 21872054]

26. Marroquin-Cardona AG, Johnson NM, Phillips TD, Hayes AW. Food Chem Toxicol. 2014; 69:220. [PubMed: 24769018]

27. Mady MS, Mohyeldin MM, Ebrahim HY, Elsayed HE, Houssen WE, Haggag EG, Soliman RF, El Sayed KA. Bioorg Med Chem. 2016; 24(2):113. [PubMed: 26692349]

28. Du L, Feng T, Zhao B, Li D, Cai S, Zhu T, Wang F, Xiao X, Gu Q. J Antibiot (Tokyo). 2010; 63:165. [PubMed: 20186171]

29. Koizumi Y, Arai M, Tomoda H, Ōmura S. Biochim Biophys Acta. 2004; 1693:47. [PubMed: 15276324]

30. Zheng CJ, Sohn MJ, Lee S, Kim WG. PLoS ONE. 2013; 8:e78922. [PubMed: 24312171]

31. Overy DP, Nielsen KF, Smedsgaard J. J Chem Ecol. 2005; 31:2373. [PubMed: 16195849]

32. van den Berg MA, Albang R, Albermann K, Badger JH, Daran JM, Driessen AJ, Garcia-Estrada C, Fedorova ND, Harris DM, Heijne WH, Joardar V, Kiel JA, Kovalchuk A, Martin JF, Nierman WC, Nijland JG, Pronk JT, Roubos JA, van der Klei IJ, van Peij NN, Veenhuis M, von Dōhren H, Wagner C, Wortman J, Bovenberg RA. Nat Biotechnol. 2008; 26:1161. [PubMed: 18820685]

33. Garcia-Estrada C, Ullan RV, Albillos SM, Fernandez-Bodega MA, Durek P, von Dohren H, Martin JF. Chem Biol. 2011; 18:1499. [PubMed: 22118684]

34. Ali H, Ries MI, Nijland JG, Lankhorst PP, Hankemeier T, Bovenberg RA, Vreeken RJ, Driessen AJ. PLoS ONE. 2013; 8:e65328. [PubMed: 23776469]

35. Ries MI, Ali H, Lankhorst PP, Hankemeier T, Bovenberg RA, Driessen AJ, Vreeken RJ. J Biol Chem. 2013; 288:37289. [PubMed: 24225953]

36. Fenical, W.; Jensen, PR.; Cheng, XC. Avrainvillamide, a cytotoxic marine natural product, and derivatives thereof. US Patent. 6,066,635. May 23. 2000

37. Wang XR, You JL, King JB, Powell DR, Cichewicz RH. J Nat Prod. 2012; 75:707. [PubMed: 22400916]

38. Peng JX, Gao HQ, Li J, Ai J, Geng MY, Zhang GJ, Zhu TJ, Gu QQ, Li DH. J Org Chem. 2014; 79:7895. [PubMed: 25089636]

$J$ Am Chem Soc. Author manuscript; available in PMC 2017 September 07. 
39. Sugie Y, Hirai H, Inagaki T, Ishiguro M, Kim YJ, Kojima Y, Sakakibara T, Sakemi S, Sugiura A, Suzuki Y, Brennan L, Duignan J, Huang LH, Sutcliffe J, Kojima N. J Antibiot (Tokyo). 2001; 54:911. [PubMed: 11827033]

40. Qian-Cutrone J, Huang S, Shu YZ, Vyas D, Fairchild C, Menendez A, Krampitz K, Dalterio R, Klohr SE, Gao Q. J Am Chem Soc. 2002; 124:14556. [PubMed: 12465964]

41. von Nussbaum F. Angew Chem Int Ed. 2003; 42:3068.

42. Wulff JE, Siegrist R, Myers AG. J Am Chem Soc. 2007; 129:14444. [PubMed: 17958425]

43. Wulff JE, Herzon SB, Siegrist R, Myers AG. J Am Chem Soc. 2007; 129:4898. [PubMed: 17397160]

44. Mikkola R, Andersson MA, Hautaniemi M, Salkinoja-Salonen MS. Toxicon. 2015; 99:58. [PubMed: 25804991]

45. Herzon SB, Myers AG. J Am Chem Soc. 2005; 127:5342. [PubMed: 15826171]

46. Baran PS, Guerrero CA, Hafensteiner BD, Ambhaikar NB. Angew Chem Int Ed. 2005; 44:3892.

47. Artman GD, Grubbs AW, Williams RM. J Am Chem Soc. 2007; 129:6336. [PubMed: 17455936]

48. Ideguchi T, Yamada T, Shirahata T, Hirose T, Sugawara A, Kobayashi Y, Omura S, Sunazuka T. J Am Chem Soc. 2013; 135:12568. [PubMed: 23957424]

49. Hafensteiner BD, Escribano M, Petricci E, Baran PS. Bioorg Med Chem Lett. 2009; 19:3808. [PubMed: 19423345]

50. Beckett AH, Sheikh AH. J Pharm Pharmacol. 1973; 25(Suppl):171P.

51. Kadlubar FF, McKee EM, Ziegler DM. Arch Biochem Biophys. 1973; 156:46. [PubMed: 4147171]

52. Bondon A, Macdonald TL, Harris TM, Guengerich FP. J Biol Chem. 1989; 264:1988. [PubMed: 2914890]

53. Cashman JR, Yang ZC, Hogberg T. Chem Res Toxicol. 1990; 3:428. [PubMed: 2151930]

54. Clement B, Lustig KL, Ziegler DM. Drug Metab Dispos. 1993; 21:24. [PubMed: 8095222]

55. Rodriguez RJ, Proteau PJ, Marquez BL, Hetherington CL, Buckholz CJ, O’Connell KL. Drug Metab Dispos. 1999; 27:880. [PubMed: 10421614]

56. Sun H, Ehlhardt WJ, Kulanthaivel P, Lanza DL, Reilly CA, Yost GS. J Pharmacol Exp Ther. 2007; 322:843. [PubMed: 17502430]

57. Barbara JE, Kazmi F, Parkinson A, Buckley DB. Drug Metab Dispos. 2013; 41:1012. [PubMed: 23404373]

58. Garcia-Estrada C, Ullan RV, Albillos SM, Fernandez-Bodega MA, Durek P, von Dohren H, Martin JF. Chem Biol. 2011; 18:1499. [PubMed: 22118684]

59. Ries MI, Ali H, Lankhorst PP, Hankemeier T, Bovenberg RA, Driessen AJ, Vreeken RJ. J Biol Chem. 2013; 288:37289. [PubMed: 24225953]

60. Gober C, Joullie MM. Athens Journal of Sciences. 2015; 3:257.

61. Sun H, Ehlhardt WJ, Kulanthaivel P, Lanza DL, Reilly CA, Yost GS. J Pharmacol Exp Ther. 2007; 322:843. [PubMed: 17502430]

62. Cashman JR, Xiong YN, Xu L, Janowsky A. J Pharmacol Exp Ther. 1999; 288:1251. [PubMed: 10027866]

63. Sustmann R, Trill H. Angew Chem Int Ed. 1972; 11:838.

64. Scott PM, Polonsky J, Merrien MA. J Agric Food Chem. 1979; 27:201.

65. Silva, JVd; Fill, TP.; Lotufo, LV.; Pessoa, CdO; Rodrigues-Filho, E. Helv Chim Act. 2014; 97:1345.

66. Roy A, Schneller SW. Org Lett. 2005; 7:3889. [PubMed: 16119924]

67. Nising CF. Chem Soc Rev. 2010; 39:591. [PubMed: 20111783]

68. Li S, Finefield JM, Sunderhaus JD, McAfoos TJ, Williams RM, Sherman DH. J Am Chem Soc. 2012; 134:788. [PubMed: 22188465]

69. Shangguan N, Hehre WJ, Ohlinger WS, Beavers MP, Joullie MM. J Am Chem Soc. 2008; 130:6281. [PubMed: 18412344]

70. Williamson KS, Michaelis DJ, Yoon TP. Chem Rev. 2014; 114:8016. [PubMed: 24754443]

71. Padwa A, Koehler KF. Heterocycles. 1986; 24:611.

J Am Chem Soc. Author manuscript; available in PMC 2017 September 07. 
72. Shindo H, Umezawa B. Chem Pharm Bull (Tokyo). 1962; 10:492. [PubMed: 13912021]

73. Trimble LA, Sumarah MW, Blackwell BA, Wrona MD, Miller JD. Tetrahedron Lett. 2012; 53:956.

74. Shan WG, Ying YM, Yu HN, Liu WH, Zhan ZJ. Helv Chim Act. 2010; 93:772.

75. Kozlovsky AGV, NG, Reshetilova TA, Sakharovsky VG, Baskunov BP, Seleznyov SG. Prikl Biohim Mikrobiol. 1994; 30:410.

76. Ouchaou K, Maire F, Salo O, Ali H, Hankemeier T, van der Marel GA, Filippov DV, Bovenberg RA, Vreeken RJ, Driessen AJ, Overkleeft HS. Chembiochem. 2015; 16:915. [PubMed: 25766600]

77. Payne KA, White MD, Fisher K, Khara B, Bailey SS, Parker D, Rattray NJ, Trivedi DK, Goodacre R, Beveridge R, Barran P, Rigby SE, Scrutton NS, Hay S, Leys D. Nature. 2015; 522:497. [PubMed: 26083754]

78. Yang J. Synlett. 2012; 16:2293. 

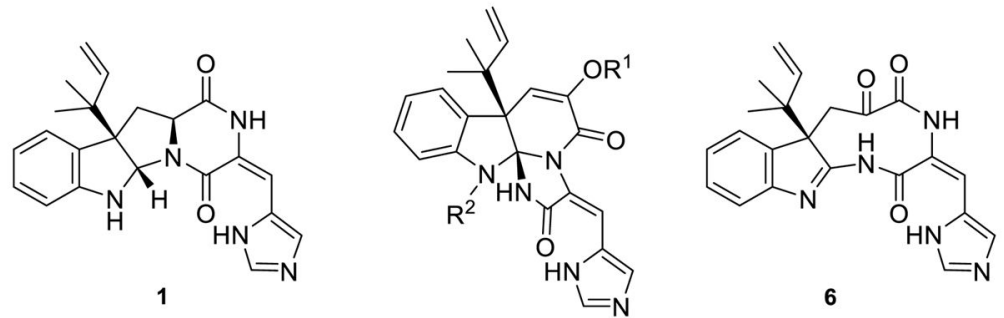

$$
\begin{aligned}
& 2 \mathrm{R}^{1}=\mathrm{CH}_{3}, \mathrm{R}^{2}=\mathrm{OCH}_{3} \\
& 3 \mathrm{R}^{1}=\mathrm{H}, \mathrm{R}^{2}=\mathrm{OCH}_{3} \\
& 4 \mathrm{R}^{1}=\mathrm{R}^{2}=\mathrm{H} \\
& 5 \mathrm{R}^{1}=\mathrm{H}, \mathrm{R}^{2}=\mathrm{OH}
\end{aligned}
$$

Figure 1.

Roquefortine C (1) and derived alkaloids oxaline (2), meleagrin (3), glandicoline A (4), and glandicoline B (5). The 1,4-diazonane-2,5,6-trione 6 was proposed by Steyn and Vleggaar 22 as an intermediate in the biosynthesis of 4 . 
<smiles>C=CC(C)(C)C12CC3C(=O)N/C(=C/c4cnc[nH]4)C(=O)N3C1=[N+]([O-])c1ccccc12</smiles><smiles></smiles>

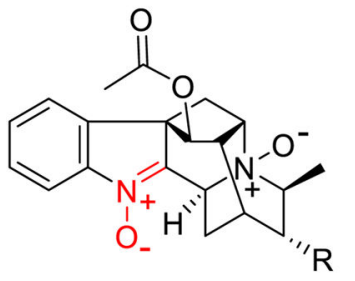

$9 \mathrm{R}=\mathrm{CO}_{2} \mathrm{H}$

$10 \mathrm{R}=\mathrm{CHO}$

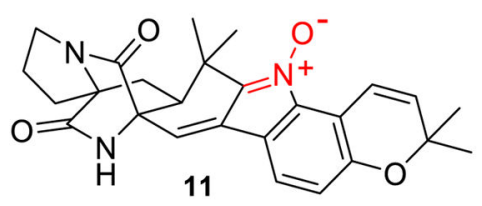

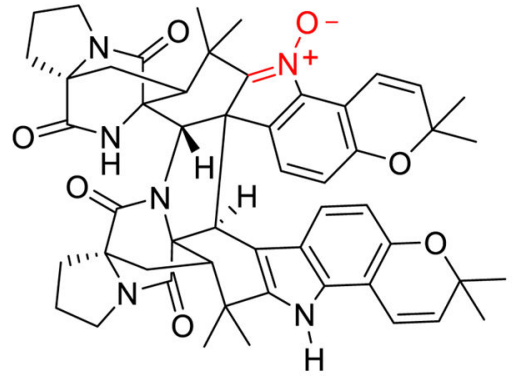

12

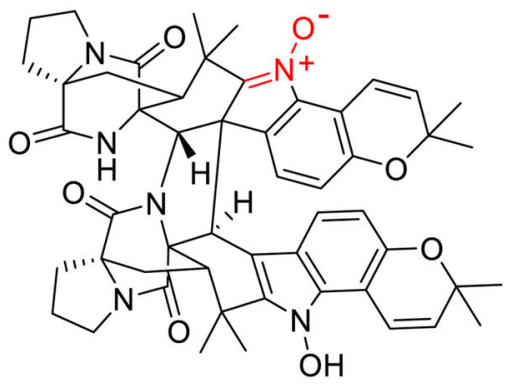

13

Figure 2. Known indolic nitrones

Roquefortine L (7) is a labile intermediate in the biosynthesis of $\mathbf{2}$. Indolic nitrone bearing natural products versicamide $\mathrm{E}(\mathbf{8})$, alstoyunine $\mathrm{D}(\mathbf{9})$, perakine $N^{1}, N^{4}$-dioxide (10), avrainvillamide (11), waikialoid A (12), and stephacidin B (13). 

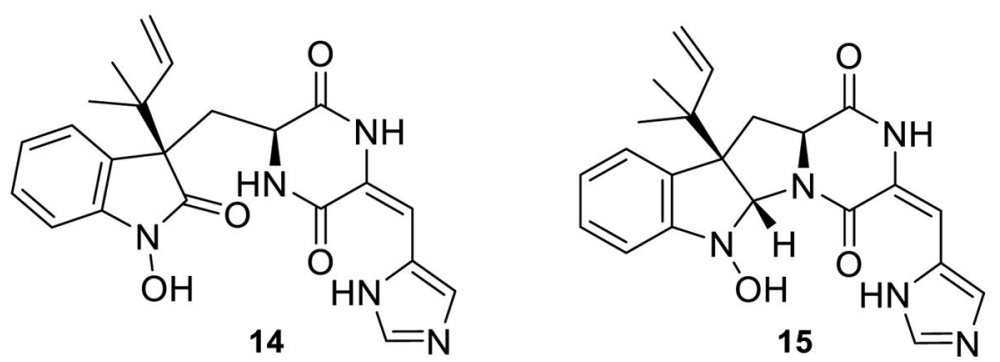

Figure 3.

Reactions with OxaD and $\mathbf{1}$ led to the detection of a hydroxylamine intermediate $\mathbf{1 5}$ and the hydrolysis product 14. 
<smiles>C=CC(C)(C)C12C[C@H]3C(=O)N/C(=C/c4cnc[nH]4)C(=O)N3[C@H]1Nc1ccccc12</smiles><smiles>C=CC(C)(C)[C@]12C[C@H]3C(=O)N/C(=C\c4c[nH]cn4)C(=O)N3[C@H]1Nc1ccccc12</smiles><smiles>C=CC(C)(C)[C@]12C[C@H]3C(=O)N/C(=C/c4cnc[nH]4)C(=O)N3[C@H]1Nc1ccc(Br)cc12</smiles><smiles>[Z17]C(C)(C)[C@]12C[C@@H]3C(=O)N/C(=C/c4cnc[nH]4)C(=O)N3[C@H]1Nc1ccc(I)cc12</smiles><smiles>C=CC(C)(C)[C@@]12C[C@H]3C(=O)N/C(=C/c4cnc(SO)[nH]4)C(=O)N3[C@H]1Nc1ccccc12</smiles><smiles>C=CC(C)(C)c1nc[nH]c1/C=C1/NC(=O)C2CC(C(C)(C)C=C)(c3ccccc3N2)[C@H]1C</smiles>

Figure 4.

Semisynthetic roquefortine $\mathrm{C}$ derivatives. Modifications to the roquefortine $\mathrm{C}$ scaffold highlighted in red. 
<smiles>C=CC(C)(C)[C@]12C[C@H]3C(=O)N/C(=C/c4cnc[nH]4)C(=O)N3C1=[N+]([O-])c1ccccc12</smiles>

$\mathrm{TTN}=2019$<smiles>C=CC(C)(C)[C@]12C[C@H]3C(=O)N/C(=C/c4cnc[nH]4)C(=O)N3C1=[N+]([O-])c1ccc(Br)cc12</smiles>

TTN $=1743$

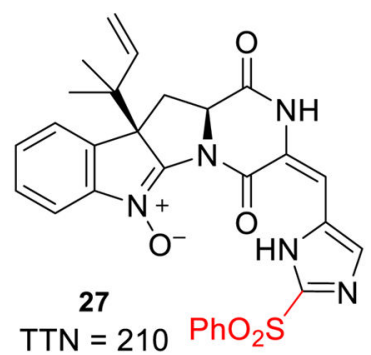<smiles></smiles><smiles>C=CC(C)(C)[C@]12C[C@H]3C(=O)N/C(=C/c4cnc[nH]4)C(=O)N3C1=[N+]([O-])c1ccc(I)cc12</smiles>

$\mathrm{TTN}=790$<smiles></smiles>

$\mathrm{TTN}=2424$

Figure 5.

Modifications to the native substrate $\mathbf{1}$ at several positions were processed by OxaD. TTN was calculated as moles product/moles enzyme. 


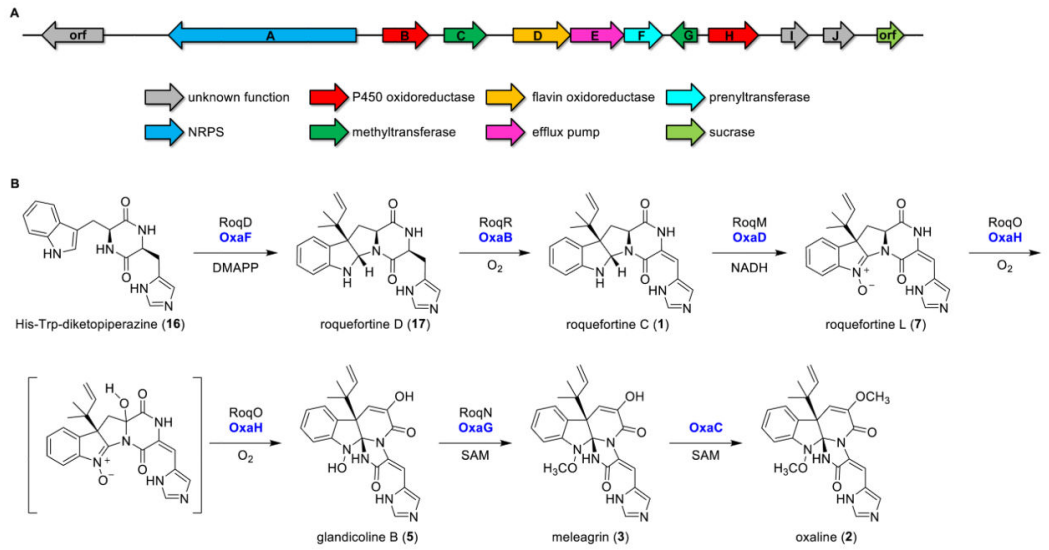

Scheme 1. Oxaline biosynthetic gene cluster

(A) Schematic representation of the ORFs in the oxaline (oxa) gene cluster. (B) Proposed biosynthetic pathway in $P$. oxalicum F30. The homologous enzymes from the roquefortine $\mathrm{C} /$ meleagrin (roq) gene cluster in $P$. chrysogenum are shown. A second methyltransferase, OxaC, lacks a homolog in $P$. chrysogenum. 


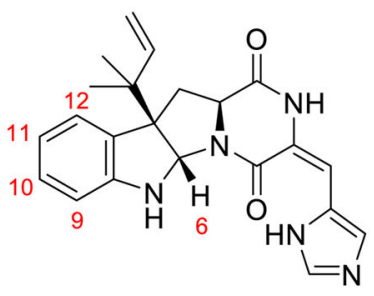

1

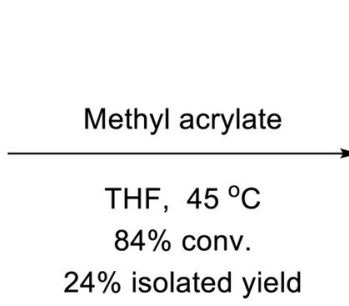

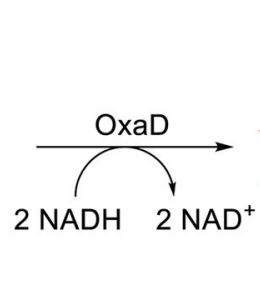

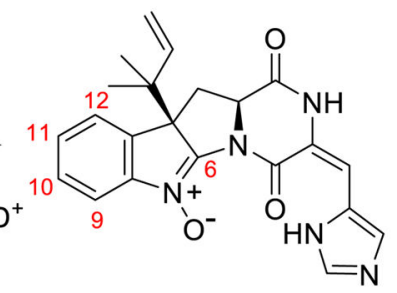

7

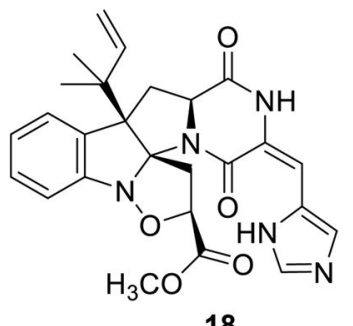

Scheme 2.

Roquefortine L (7) undergoes 1,3-dipolar cycloaddition with methyl acrylate to generate $\mathbf{1 8 .}$ 
A
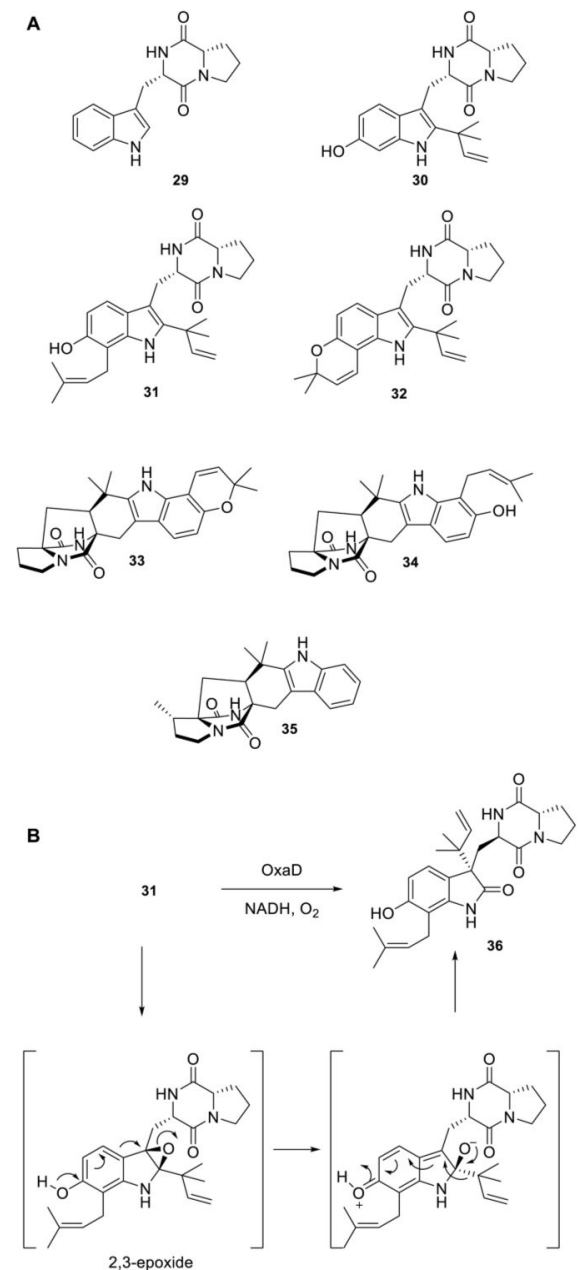

Scheme 3. OxaD reactivity with notoamides

(A) Synthetic notoamides tested with OxaD. Only 31 was converted by the enzyme. (B) Pinacol-like rearrangement of the OxaD catalyzed 2,3-indole epoxidation on $\mathbf{3 1}$ gives rise to the novel product $\mathbf{3 6}$. 


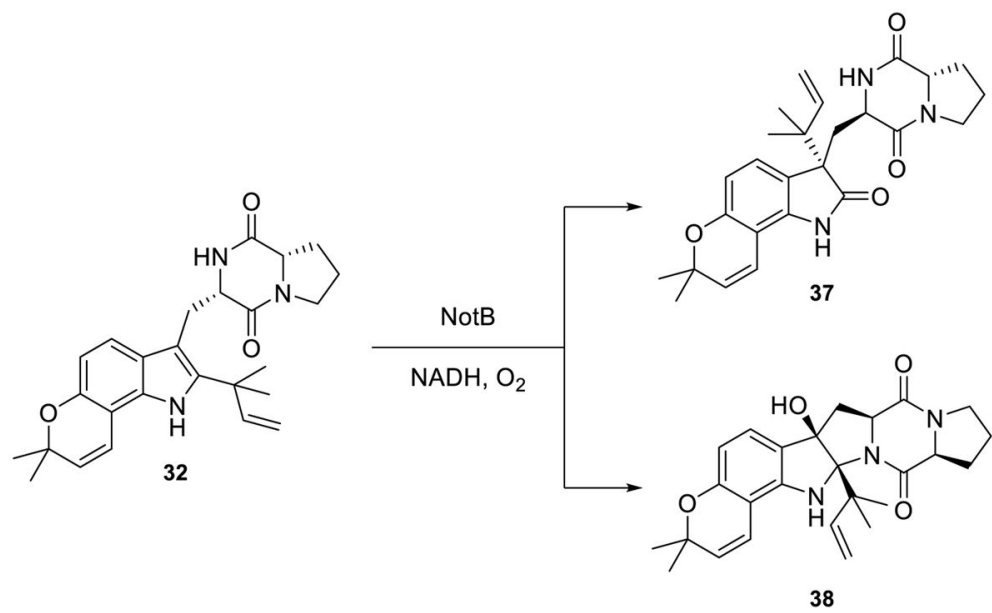

Scheme 4.

NotB-catalyzed formation of notoamides C (37) and D (38) from notoamide E (32). 


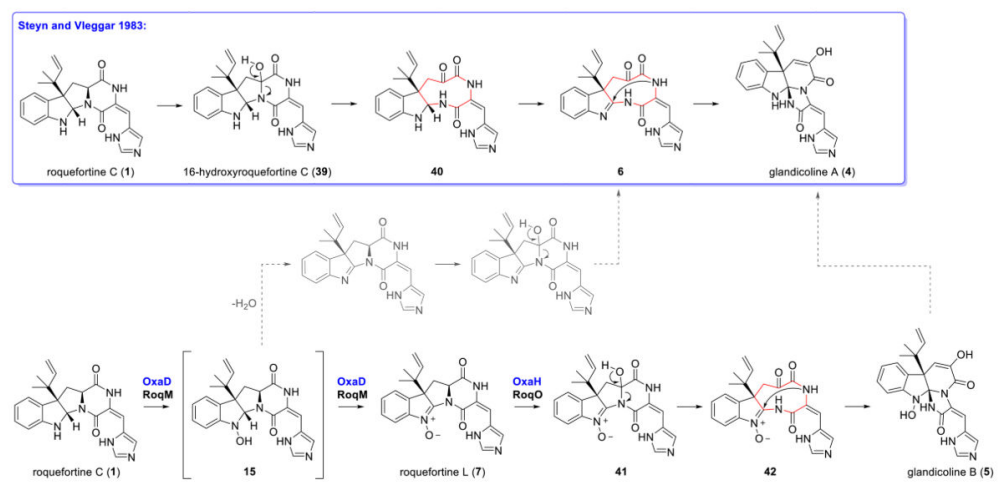

Scheme 5. Proposed biogenesis of glandicoline A (4) and B (5)

The nitrone intermediate $\mathbf{7}$ described by Ries et al. and in this work is likely a key priming step for the rearrangement to 6 . Compound 5 is not observed in $P$. chrysogenum or $P$. oxalicum $\mathrm{F} 30$ but is a known natural product. One possible route to $\mathbf{5}$ is through dehydration of the hydroxylamine intermediate $\mathbf{1 5}$ followed by hydroxylation and rearrangement. Enzymatic processing of $\mathbf{5}$ to $\mathbf{4}$ must also be considered. 